\title{
Palliative Chaplain Spiritual Assessment Progress Notes
}

\author{
Paul Galchutt and Judy Connolly
}

\section{Background}

Palliative care is a field of medicine focused on caring for people with serious illness. Unique to palliative care is the interprofessional team delivery model. In the United States, the team typically consists of physicians, non-physician prescribing and treatment providers (e.g., advanced practice nurses), psychotherapists (e.g., clinical social workers), and a chaplain. The holistic nature of palliative care is summarized in eight domains (Ferrell et al. 2018). The fifth domain, relating to existential, religious, and spiritual aspects, is the area in which the chaplain conceptually serves as the specialist. Based on this fifth domain, the National Consensus Project Clinical Practice Guidelines for Quality Palliative Care (2013) cites, "Preferred Practice 20: Develop and document a plan based on assessment of religious, spiritual, and existential concerns using a structured instrument and integrate the information obtained from the assessment into the palliative care plan" (p. 64).

Palliative care chaplains contribute to this plan through spiritual assessment. A fairly recent white paper for palliative spirituality (Puchalski et al. 2009) highlights the importance of the spiritual care role for all palliative interprofessionals. It also makes a distinction between the specialist role of chaplains, focused on the patients' existential, spiritual, and religious domain, and the generalist role of non-chaplain palliative team members such as physicians, advanced practice providers, and clinical social workers (Puchalski et al. 2009).

Spiritual assessment is an essential component of healthcare chaplaincy in the United States. The US-based Association of Professional Chaplains lists spiritual assessment as the first standard, among 15, Standards of Practice for Professional Chaplains. It states, "The chaplain gathers and evaluates relevant information regarding the care recipient's spiritual, religious, emotional and relational needs and

P. Galchutt $(\bowtie) \cdot$ J. Connolly

M Health Fairview, Minneapolis, MN, USA

e-mail: pgalchu1@fairview.org 
resources" (2015, p. 1). This standards document grants flexibility for the form in which a chaplain records this information about a spiritual assessment into the patient electronic medical record (EMR). For some healthcare chaplains, spiritual assessment can mean a diagnosis developed, for example, around the issue of belonging or forgiveness. For other chaplains, spiritual assessment can mean inputting point-and-click logistical data in the EMR concerning where the visit occurred, how long it lasted, or the basic interventions facilitated. There is some evidence (Tartaglia et al. 2016), however, that chaplains prefer to transmit the information through narrative text or what is referred to as the progress note in the EMR. Our contribution to this volume is focused on the spiritual assessment conducted by a palliative care chaplain as it takes the form of a narrative progress note. One purpose of this progress note is to contribute to the palliative care team's shared care plan for the patient.

This plan is collaboratively developed with the chaplain and interprofessional partners on the palliative care team based on a structured spiritual assessment instrument. The palliative spirituality white paper (Puchalski et al. 2009), which was developed as part of a consensus project, stated that chaplains' spiritual assessments are models of "interpretive frameworks [...] based on listening to a patient's story as it unfolds" (p. 893). Over the years, many of these spiritual assessment models have been developed by chaplains, for chaplains (Fitchett 2017) to serve as templates for narrative progress note completion.

Some evaluation, albeit limited and sporadic, of healthcare chaplains' spiritual assessment progress notes exists from non-chaplains. A Duke University team (Choi et al. 2019) studied chaplain progress notes as a component of an intensive care unit setting which featured the views of non-chaplain clinicians. They reported a prevalence of attending physicians $(31 \%)$ and nurses $(23 \%)$ reading chaplain progress notes (p. 94). While not overly large sample sizes (attending physicians, $n=29$; nurses, $n=139$ ), these data are significant due to the scarcity of such data anywhere within the peer-reviewed literature. Also noteworthy are observations made by another Duke University team (2016) of a medical student (Lee) and two physicians (Curlin and Choi), in their descriptive study of chaplain progress notes also from within an intensive care unit. They wrote of chaplains using "code language" that does not "convey the deeper spiritual connections" (Lee et al. 2016, 194) chaplains have with patients and families. They also note the importance of "standardization" (p. 195) and how it is lacking within chaplain progress notes documented in the EMR.

While chaplains are recognized for their specialized spiritual assessment role within palliative care, a gap remains between what and how a chaplain reports this information through progress notes as well as how it is relevant to the overall care plan. Knowing there is limited evaluation in the literature from non-chaplains regarding chaplain spiritual assessment progress notes, a need exists for a systematic data collection and analysis of the views and perceptions from non-chaplain palliative care team members as the primary readers of these notes. The primary aim then of this study was to ask palliative non-chaplain team members what is most helpful as well as missing from a chaplain's spiritual assessment progress note. 
To facilitate this aim to glean the perceptions and perspectives of non-chaplains, seven focus groups were conducted.

The anticipated benefits of these focus groups were quality improvement through knowledge gained or insights offered for what a chaplain communicates to palliative care team members. A palliative chaplain's spiritual assessment progress notes are created through and informed by a narrative approach (Puchalski et al. 2009) while making a deeper spiritual connection (Lee et al. 2016). Each patient's values (Frank 2010) will more likely emerge through knowing each person (Cassell 2004). We conducted a descriptive, exploratory study of seven focus groups with the primary aim to discover what content is most helpful as well as missing from the perspective of non-chaplain palliative care team members. This study identifies both descriptive and summary content themes to address the gap between what a chaplain reports through the progress note and how it is relevant to the most heightened needs of non-chaplain palliative providers.

\section{Study Design and Data Collection}

Having had the rich experience of being an inpatient palliative care chaplain for 10 years, Paul has firsthand concrete practice with seeking to communicate information in a progress note not knowing if it was being read and, if read, whether it was making a difference. Motivation behind this project was to ask, essentially, what information can best help chaplains make a relevant and meaningful difference together with palliative care team members to reduce suffering and improve quality of life.

We conducted focus groups with non-chaplain palliative care team members to address the research question: What content is most helpful as well as missing from palliative chaplain spiritual assessment progress notes as perceived by non-chaplain palliative care team members?

90-minute focus groups were conducted approximately once every 10 days over a span of roughly 3 months from September to November 2018. Participants were from six palliative care teams based out of six acute care hospital locations within a metropolitan area within the upper Midwest region of the United States. One of the six teams was based out of a children's hospital. Two focus groups were hosted in this pediatric setting. The other five focus groups were hosted with the inpatient palliative care teams caring for adult patients.

Each palliative care team consisted, primarily, of physicians, non-physician prescribing and treatment providers (e.g., advanced practice nurses), psychotherapists (e.g., clinical social workers), and nurses such as care coordinators. Also participating was a child-family life specialist as well as a massage therapist. A discussion guide (Table 1) was used to invite the views and perceptions of participants as the focus group conversations unfolded.

During the data analysis processes, we developed concepts and categories to identify patterns and trends by comparing "one segment of data with another to identify similarities and differences" (Krueger and Casey 2015, 157). As the analysis 
Table 1 Key focus group questions

1. Read Introduction. Participant introductions along with opening question - would you share your name and how long have you been involved in palliative care?

2. So, now we'd like for you all to share with each other, what do you think about the chaplain's spiritual assessment? (Probes: Do you read it? How often?)

3. Tell us about what is missing from the chaplain's spiritual assessment progress note.

4. Think back to over the months or years you've been in palliative care and tell us about a memory that stands out as useful from something you've read in a chaplain's spiritual assessment progress note.

5. Let's talk about what content is in the spiritual assessment progress note.

(a) Take this piece of paper and write down which three things from the spiritual assessment are most helpful to you in your work.

(b) OK. Let's go around the table and each of you tell me what you wrote down and give me a one-sentence description of that thing. (List each item on a flip chart. If an item is mentioned more than one time, put a check mark next to it for each additional time it is mentioned.)

(c) (Pick the one with the most check marks and say) A number of you said $\mathrm{X}$ was a strength. Talk more about that. (Discuss two or three items - as time allows.)

6. Now, let's talk about what's missing from the spiritual assessment progress note. Let's use the same process.

(a) Using the same piece of paper, write down three things missing from the spiritual assessment.

(b) OK. Let's go around the table and each of you tell me what you wrote down and give me a one-sentence description of that thing. (List each item on a flip chart. If an item is mentioned more than one time, put a check mark next to it for each additional time it is mentioned.)

(c) (Pick the one with the most check marks and say) A number of you said X was missing. Talk about that. What about $\mathrm{X}$ is important to the spiritual assessment and your work with the chaplain. (Discuss two or three things as time allows.)

7. So, we've talked about features within the spiritual assessment progress note. Thinking about all of those, I'd like for each of you to now share what you see as the most important thing we've discussed and tell us why you feel that way.

8. Conclusion: Oral summary of focus group provided by the assistant moderator

partners, we then met again to compare and contrast the groups framed by these categories for a second stage of coding as well as to strengthen reliability. For the next stage of the constant comparative method of theme development, defined themes with representative quotes from the data were proposed based upon the initial categories. The analysis partners, finally, confirmed theme selection with one another prior to manuscript creation to further enhance reliability of the data.

In total, 42 non-chaplain, palliative care interprofessionals participated in the 7 focus groups occurring during Fall 2018. Focus group sizes ranged from 4 to 8 participants $($ mean $=6$ ). Table 2 displays the demographic characteristics. Participant ages were between 25 and 62 years of age (mean age 43). Most participants were white $(91 \%)$ and female $(69 \%)$. Among the interprofessional participants are physicians (41\%), non-physician prescribing and treatment providers $(21 \%)$, nurses $(17 \%)$, and psychotherapists (17\%). Although many participants are identified as Christian $(62 \%)$, there was a noteworthy prevalence $(16 \%)$ with no religious or spiritual affiliation. While this was also an experienced assembly of healthcare pro- 
Table 2 Characteristics of non-chaplain interprofessional palliative care team members $(\mathrm{N}=42)$

\begin{tabular}{|c|c|}
\hline & Total $(n=42)$ \\
\hline Characteristic & $f(\%)$ \\
\hline \multicolumn{2}{|l|}{ Vocation } \\
\hline $\begin{array}{l}\text { Physician } \\
\text { Advanced practice provider } \\
\text { Registered nurse } \\
\text { Clinical social worker } \\
\text { Child-family life specialist } \\
\text { Massage therapist }\end{array}$ & $\begin{array}{l}17(41) \\
9(21) \\
7(17) \\
7(17) \\
1(2) \\
1(2)\end{array}$ \\
\hline \multicolumn{2}{|l|}{ Age } \\
\hline $\begin{array}{l}\text { Mean = 43 years old } \\
25-36 \\
37-49 \\
50-62\end{array}$ & $\begin{array}{l}12(29) \\
18(42) \\
12(29)\end{array}$ \\
\hline \multicolumn{2}{|l|}{ Palliative work experience } \\
\hline $\begin{array}{l}<1 \text { year }-9 \text { years } \\
10-19 \text { years } \\
20-28 \text { years } \\
\end{array}$ & $\begin{array}{l}29(69) \\
11(26) \\
2(5) \\
\end{array}$ \\
\hline \multicolumn{2}{|l|}{ Gender } \\
\hline $\begin{array}{l}\text { Female } \\
\text { Male } \\
\text { Gender non-conforming }\end{array}$ & $\begin{array}{l}29(69) \\
12(29) \\
1(2) \\
\end{array}$ \\
\hline \multicolumn{2}{|l|}{ Race } \\
\hline $\begin{array}{l}\text { White } \\
\text { African American } \\
\text { Hispanic } \\
\text { Korean American }\end{array}$ & $\begin{array}{l}38(91) \\
2(5) \\
1(2) \\
1(2) \\
\end{array}$ \\
\hline \multicolumn{2}{|l|}{ Religion } \\
\hline $\begin{array}{l}\text { Christian } \\
\text { No faith/spirituality indicated } \\
\text { Jewish } \\
\text { Unitarian Universalist } \\
\text { Spiritual, but not religious } \\
\text { Agnostic }\end{array}$ & $\begin{array}{l}26(62) \\
7(16) \\
3(7) \\
2(5) \\
2(5) \\
2(5)\end{array}$ \\
\hline
\end{tabular}

${ }^{a}$ Advanced practice provider (non-physician healthcare provider with scripting authority. Either an advanced practice nurse or a clinical nurse specialist within this sample)

fessionals with a continuum beginning with less than 1 year of experience extending to 28 years, the highest percentage $(69 \%)$ of participants have been serving in palliative care for 9 years or less.

\section{Results}

Twelve themes, in total, arose from the seven focus groups in response to the research question concerning what content is most helpful as well as missing from palliative chaplain spiritual assessment progress notes. As shown in Table 3, these 
Table 3 Themes for palliative chaplain progress notes - focus group research “...the things that are missing are the things that are helpful"

\begin{tabular}{l|l}
\hline Descriptive content & Summary content \\
\hline $\begin{array}{l}\text { 1. Decision-making } \\
\text { Religion/spirituality }\end{array}$ & $\begin{array}{l}\text { 1. Logistics } \\
\text { Why there? } \\
\text { Time spent? }\end{array}$ \\
\hline $\begin{array}{l}\text { 2. Suffering } \\
\text { Religion/spirituality }\end{array}$ & 2. Synthesis \\
\hline $\begin{array}{l}\text { 3. Coping } \\
\text { Religion/spirituality }\end{array}$ & $\begin{array}{l}\text { 3. Scales } \\
\text { Suffering/coping } \\
\text { Decision-making }\end{array}$ \\
\hline $\begin{array}{l}\text { 4. Religion/spirituality } \\
\text { Spectrum } \\
\begin{array}{l}\text { Description } \\
\text { Importance }\end{array}\end{array}$ & $\begin{array}{l}\text { 4. Recommendations to staff } \\
\text { Language } \\
\text { Religious/spiritual practices }\end{array}$ \\
\hline $\begin{array}{l}\text { 5. Story } \\
\text { Understanding of illness } \\
\text { Spiritual story }\end{array}$ & 5. Needs/goals of care/action plan \\
\hline $\begin{array}{l}\text { 6amily } \\
\text { Support }\end{array}$ & \\
\hline Dynamics & \\
\hline 7. Perception of emotion & \\
\hline
\end{tabular}

12 themes and subthemes were categorized into 2 overall groupings, Descriptive Content ( 7 themes) and Summary Content (5 themes). These themes are organized by what was both simultaneously helpful and missing as a research participant expressed "...the things that are missing are the things that are helpful."

\subsection{Descriptive Content Themes}

Through our analysis, seven themes and supporting subthemes emerged related to the descriptive content non-chaplain palliative care team members believe should be addressed and incorporated into a palliative chaplain's progress note. Of note, while the theme of religion and spirituality is specified as a distinct descriptive theme based on the participant's views, it also frequently appeared as a subtheme often integrated into the other themes discussed. Krueger and Casey (2015) write about analytic factors such as extensiveness, frequency, specificity, and emotion related to focus group data being easier to discern from the text if the focus group moderators are also the research analysts as was true with this research project.

\subsubsection{Decision-Making}

By serving in both the moderator and analysis roles, it was clear that decisionmaking was the most discussed theme across all groups (extensiveness) and mentioned among all the themes with the most frequency within each group. 
Decision-making also prompted the most stories (specificity) and generated the most passion (emotion), especially within the context of palliative care teams facilitating goals of care discussions concerning end of life when conflicting values between family members emerged or when the primary medical team's recommended course for treatment was not being followed.

Decision-making was also discussed as the area participants felt the most pressure about and about which the stakes were often highest within life-and-death patient decision-making situations. They explained a chaplain's detailed reporting about the subtheme of a patient's religion/spirituality and how or why it conflicts with a medically recommend course as being most helpful. Participants further explained having conversations about these matters with chaplains in team rounds but that it was not in the progress note as often as desired. One participant also named the significance for not only knowing religious or cultural information for actionable decision-making but also for personal understanding of the patient and family: "It's very important to know, you know, how one's religion or culture affects their decision making is paramount in understanding."

The participants were also knowledgeable about chaplains inviting conversation about and receiving information from patients and families about their sense of future amid serious illness. Participants expressed their expectation that a chaplain would be descriptively attentive to this information in a progress note when a patient shared their sense of hope or future, as a second subtheme, related to decisionmaking. One participant simply and specifically named: "Like what is their hope and what are they hoping for."

\subsubsection{Suffering}

With the relief of suffering or distress being central to the principles of palliative care, it makes sense that palliative care chaplains are expected, based on these focus groups, to address this theme as essential to palliative care in chaplaincy spiritual assessment. In addition to suffering being addressed from a whole person perspective such as paying attention to "trauma, grief, and loss," it was also clear that chaplains are expected to be specialists concerning religious and/or spiritual suffering and to have that reflected in the progress note.

The wish for chaplaincy notation about a patient's overall sense of suffering emerged, including what this means related to physical symptoms. A participant remarked on wanting information concerning this data in a chaplain's note:

Not that I go to the chaplain, primarily, for their thoughts on the patient's comfort level, but it is helpful sometimes if they...can identify at least if somebody is really in distress. Like maybe, because of symptoms, maybe a combination....

Palliative team members also discussed recognizing that suffering has various dimensions, along with or beyond the physical pain or other forms of bodily distress. The subtheme of religious or spiritual suffering was discussed as palliative care team members as spiritual generalists are aware of and look for information in the chaplain notes about "some kind of spiritual issue." 


\subsubsection{Coping}

Coping exists together with suffering/distress. Focus group participants often reflected on how it is helpful to read in a progress note about some aspect of how a patient is adjusting or what their "strengths" are, overall, related to their serious illness circumstances and what it means for them in terms of their personal suffering/ distress. One palliative clinician specified:

...the chaplain's perspective on how the patient copes and how they are coping, and kind of where they're at in this process. It's, that's valuable information.

There was also substantive conversation among the teams regarding the subtheme of a chaplain's assessment of, when pertinent, a patient's religious/spiritual sense of coping. A descriptive sense of what orients a patient or family member to that which is sacred or significant during a disorienting and uncertain time of serious illness was named as helpful. Also discussed was how this potentially positive source of coping can or has changed during illness. This sometimes appeared with non-chaplain team members also wanting to know a patient's view of dying or whether they are "at peace." One participant requested this more transcendent data: "...where is this patient spiritually, meaning, 'Are they at peace with where they are spiritually?' Is their spiritual place helpful or harmful to them right now?"

\subsubsection{Religion/Spirituality}

This thematic area is central to palliative care chaplaincy. There were no efforts made by interprofessional participants to separately define the constructs of spirituality and religion within the context of these focus groups. There was affirmation of palliative chaplains addressing a more global sense of a person's spirituality with three related, but distinct, subthemes. First, palliative team members want information about where a patient is on a "spiritual spectrum" with religion being included within that construct. One participant suggested:

I'd like to know where they fall on the spiritual spectrum. Like faith is everything versus there is no God versus I'm a spiritual person, I love nature. I want to know where they are in that realm.

While wanting to know matters such as a specific religion or where a person worships, participants asked for information on how religion or their version of spirituality shapes their "view of the world...into a way to make sense of it all." The second subtheme, description, was illustrated when the focus group conversations devoted energy to wanting a description of a patient's religion/spirituality and practices and how it "influences their decision-making," suffering, and coping, as noted above.

The third subtheme of the importance of a patient's religion or spirituality amid serious illness was named as being useful, especially concerning how it informed interprofessional members about the intensity of a worldview or belief system. One participant expressed the significance of this weighted "need" in a chaplain's note, 
"to dig into the nitty-gritty on the core issue of how is this person's belief of faith or spirituality or religion affecting their current condition." Reflecting the importance of this subtheme, stories were shared in the focus groups illustrating memorable occurrences for both when a patient's religion or spirituality was helpfully detailed in a chaplain's progress note and when it was not.

\subsubsection{Story}

It was noted by participants that being able to glean a sense of who a patient is as a person through story is helpful. With the diagnosis of any serious illness, a reconfigured story of a person's life as patient necessarily emerges. An unbidden illness has radically changed and disrupted a life. The telling of stories is often the process a patient reflexively uses to make sense of and reconstruct his/her life with serious illness and, sometimes, dying. A palliative chaplain is expected to be a "storylistener" and to integrate an appreciable interpretation and then translation of the meanings and values from these stories into, first, an understanding of illness and, second, when religion/spirituality is identifiably present, the reporting of how his/ her "spiritual story" influences illness apprehension.

When talking about gathering a sense of a patient's understanding of illness through a chaplain's note, one participant stated, "I think they're crucial to painting out the whole picture in patients like this." Another participant described not wanting an overly detailed templated note, wanting instead the essence of a patient's understanding, "It's just too much words. I just like to read a story rather than trying to read all of those same questions over and over again."

Consistent with other themes above, religion/spirituality also informed the subtheme of wanting a patient's "spiritual story." It was best summarized by one participant:

I like reading stories and so I would be interested in a spiritual story, not just the narrative you glean but what is there. Like how they've framed the spiritual story. An explanation of how a patient interprets their illness through a spiritual lens.

\subsubsection{Family}

The focus group participants indicated that it is helpful to know who the patient defines as family, whether they are involved or influential, and how supportive they are as a subtheme. Related to having a sense of who supports the patient, one of the interprofessional team members requested:

So, who's in the room, who's coming to visit this [person] and who is a potential influence?

And, what are the influences?

It was also affirmed that this support sometimes comes in the form of a patient's religious or spiritual communities in "very concrete and tangible" form as more of a "kind of existential effect." 
Participants also want it identified who is a source of conflict or produces tension in manifesting family complexity and dynamics as another subtheme. One participant noted finding this information, historically, in a chaplain's progress note and finding it relevant:

I think in the family dynamics, sometimes the spiritual care notes can have some insight into, this is the way this family comes to decisions, or this, which can be super helpful in how to approach that family in the care conference.

As is often the case with family dynamics, especially in matters of intense lifeand-death decision-making, serious illness is inescapably fraught with layers of emotion.

\subsubsection{Perception of Emotion}

Conversation in the groups also steered toward a desire for chaplains to communicate some sense of what was perceived emotionally in the room to make the interprofessional partners aware and provide some context. Whether a seriously ill patient and family are integrating a difficult diagnosis and prognosis in a way that is accepting of the medical characterization of it, or whether there is a choosing of a future version of reality that conflicts with the medical picture being painted, perceptions of that information and emotions connected with it were desired. When inpatient palliative care is consulted with the more challenging and conflicting circumstances regarding decision-making, a chaplain's insights are sought to help describe emotional tensions and create awareness for other team members. One participant narrated how this awareness is helpful to framing his/her approach with the patient:

What are you thinking when you walk into that room? What do you feel? Because I'll probably feel that same thing when I walk to that door.

\subsection{Summary Content Themes}

Connected with the seven descriptive content themes above, participants also talked about it being helpful for this content to be readily and easily accessible in a summary form in a chaplain's progress note. They expressed wanting the option to read the substantive information in the more descriptive context found in "paragraphs," as well as needing information that was immediately accessible at a glance that was "succinct" or in "bullet points." One of the participants characterized and summarized this need and challenge for both descriptive and summary content:

...one of the more challenging parts of writing a note is to figure out, to take what you've gleaned in narrative from a visit and trying to distill it down to a few points that you think that the person reading the note is going to need to understand. That's why editors write headlines and journalists write paragraphs generally [laughter]. 
Another participant provided a sense of what a chaplain's summary could include:

You know, the two-line, and again I'm kind of thinking about spiritual care writ large that, you know, 'came and prayed and offered support,' that doesn't tell me very much. But the 2-3-line summaries that kind of indicates the intersection of spirituality and medical care and decision making what they know, that is helpful.

The need for summary content is shown through the following five themes and subthemes. There are echoes of the seven descriptive content themes, weighted, within the summary content themes.

\subsubsection{Logistics}

When asking participants about what is helpful or missing, some participants responded with an ever-practical logistical request for the citing of a reason for chaplaincy involvement to be front and center as the subtheme of "why there." A participant requested it as being helpful to know, “... why they are being seen? Like, how did the chaplaincy get involved or spiritual care get involved with it?"

Additionally, participants expressed the desire for a chaplain's notation around time spent for establishing an estimation of the possible intensity or involvement of the chaplain encounter. One participant reflected on what this information could mean for his/her care with a patient:

I mean I do find it helpful for when one of my colleagues go like document prolonged care time, from here to here. I know wow, they really dug in there. And so, if I had some sense maybe of the time spent there, I would maybe know from my end how much, should I, or do I need to tack onto that or if [chaplain] spent two hours there maybe I don't need to be super diving in or I don't know.

\subsubsection{Synthesis}

Two reasons appeared from the data about the significance of a synthesis at the top in the summary section of a palliative chaplain's note. The first is that it is practical to have the most important information about a care encounter, "the really important stuff," be listed in the space where a busy partnering clinician may be more likely to read it, especially if the information culled out has been discerned to be significant. This leads to the second observation that if the information was assessed to be most important, it likely went through a process of refining discernment and consideration reflected in the quote below:

When I read a synthesized note, I'm fairly certain that the person has really thought it through and really can put words to what this thing means. And so, there's an aspect of sureness of the information and when I see that, I'm really ok, this is really a very solid bedrock. 


\subsubsection{Scale(s)}

Participants also wanted scales or some kind of a ranking or score concerning both a patient's suffering/coping continuum and decision-making to be immediately accessible in a summary section. It was discussed that one of the functions or a purpose for having a scale is to triage patients with the highest or most intense need. It is important to note that while there was a desire for a quick or easy, readable, and interpretable scale, it was also acknowledged that there may not be a quick or easy solution to the complex problem for communicating this critical information about a palliative patient experiencing distress and/or challenges with decision-making. Related to a suffering/coping continuum scale, a participant observed:

....a religious/spiritual coping score... And I'm conflicted about even putting a score, because I don't think it's quite that simple. But, what I mean by that is the information of what within their spiritual orientation is causing them challenges right now and what within their spiritual orientation is helping them and how does that kind of balance out.

Connected with, but different from a suffering/coping scale, one of the interprofessionals stated concerning a decision-making scale as well:

You know, you could almost have two scales, one of spiritual distress, like why did God do this to me? Why are my prayers not being answered that way I want them to be? You know, that kind of spiritual, real spiritual distress that's questioning their spirituality or suffering from that. And then there could almost be a different scale of, how important is your spirituality to your medical decision making, from 0-10? Right, because some people are like, not at all important. Some people like, eh, it's involved, and then for some people, it's 10 out of 10 important.

\subsubsection{Recommendations}

Participants also identified a clear need for help with language, especially with families who may have a more defined religious or cultural expression at variance from a dominant group. Requests varied from the simple hope of knowing religious leader's titles (imam, elder, pastor) within a certain community to assist in understanding and language for identifying, for example, a specific Christian expression of faith from which a mandate of waiting for a miracle may have arisen. The participants amplified how high the stakes can be in religiously unknown territory with emotionally heightened circumstances. A need was identified for language that may help staff navigate critical moments and conversations, rather than potentially sabotage them. Concerning the subtheme of language, a participant stated:

I'm looking for help with language. We're called to meet families usually in a time pressured situation when [the patient] is on the brink of death which is the worst crisis they've probably ever seen. And so, we, the language is so important. You make a mistake like that, you may not get a chance to recover or they're so stressed they fire you and you're done and you can't help anymore. So, part of what I'm looking for is language.

Additionally named as a subtheme among recommendations was citing important religious or spiritual practices for the staff, namely, other team members and 
bedside nursing, to help the patient and family on any given day and especially in time of more acute spiritual need. One of the participants illustrated an imagined situation of this subtheme's significance:

...if the chaplain has identified a coping skill that patient has, to encourage the staff to say, you know, in my interview with Mr. Smith, they coped well with prayer and so if they're struggling with anxiety at 2 o'clock in the morning, the nurses can say maybe, you know, would it be helpful if someone came to pray with you.

\subsubsection{Ongoing Needs/Goals of Care/Action Plan}

Focus group participants also expressed a fifth summary content theme as their wish to see some listing of how ongoing spiritual needs are being addressed, what goals of care the chaplain has in relation to those needs, and what is the plan of care to address those needs and meet those goals. One of the participants pointedly described in what way this could be helpful: “...this is why I'm seeing the family, this is what I'm working on, and this is how it resolved."

Another palliative interprofessional team member offered:

I had plan as well and then maybe along with that I don't know too, what are the ongoing spiritual needs that need to be addressed? Whether that's in the plan or not, but I had that too, talk to me about spiritual needs.

The significance of the palliative chaplain detailing spiritual needs and having related goals of care described in a structured, templated progress note connects back the importance of the specialist role the chaplain plays on a palliative care team related to religious, spiritual, and existential aspects of care concerning a patient's serious illness.

\section{Discussion}

We examined the views and perceptions of the non-chaplain palliative care team members. The results illustrate that decision-making is the theme where information and insight about a patient's religion/spirituality as well factors concerning a patient's story, family, and perception of emotion are most desired. While it was surprising that this was the theme most discussed by non-chaplain palliative team members, it was anticipated to be in the robust mix of themes (Wirpsa et al. 2019). The literature points to the significance of religion/spirituality for decision-making at the end of life, especially in an intensive care unit (Ernecoff et al. 2015). Decisionmaking in stressful circumstances is something palliative care teams work to lessen the burden of with a patient and family. There is also a financial cost lessened when patients near death experience high spiritual support. They are three times more likely to enter hospice compared to those with low spiritual support (Balboni et al. 2010). Additionally, those receiving poor spiritual support from a medical team cost 
on average \$2441 (US dollars) more in the final week of life compared to those who are well-supported (Balboni et al. 2011).

Of secondary importance, non-chaplain palliative care team members want a chaplain's progress notes to address patient suffering as well as to know how the patient is coping with it. Like decision-making, there is a desire to know how a patient's suffering and coping is influenced by religion/spirituality, specifically, as well as by a patient's story, family, and perception of emotion. Addressing religious/ spiritual suffering is important as it has been found, for instance, in nearly half (44\%; 40/91) of an advanced cancer population at MD Anderson Cancer Center. Also, among those with "spiritual pain" (p. 986), they had worse physical symptoms, apart from shortness of breath, as compared to those without spiritual pain (Delgado Guay et al. 2011). In other words, there is some evidence that, by addressing religious/spiritual suffering, embodied suffering can also be reduced. Focus group members also desired to know how coping, overall, and what orienting system (Pargament 2001) patients and families use to assist them in adjusting to disruptive and uncertain circumstances.

An additional surprise to the analysis process was the extent to which nonchaplain team members wanted a sense of a chaplain's perception of emotion in the narrative progress notes related to a patient and family's response to the serious illness. While related to coping, this theme was distinctive as it was identified more to be helpful for a non-chaplain palliative team member's preparation for and possible approach to care with that patient and family. While feelings were described as a part of this sense of emotion, there was also a sense that it was a perception of what was significant (Furtak 2005) for a patient.

The fourth theme worth highlighting, and not previously mentioned in the literature about a palliative chaplain's progress note, is the practical need for an efficient and weighted summary of content at the top. A participant captured this desire with, “...you don't need to scroll down or look for buried treasure." Meriting a focused discussion about what treasure needs to be at the top of the progress note, as it is not apparent in the literature, is the need for a synthesis, scales, and recommendations. Concerning the synthesis, a palliative chaplain's determination of what descriptive content emerged as most important begs for a brief description in this summary section. Related to scales, Stefanie Monod and team $(2010,2012)$ in Switzerland have developed and validated the clinically based Spiritual Distress Assessment Tool (SDAT) within a geriatric rehabilitation hospital setting. It could be argued that SDAT cannot be generalized to other countries or to a palliative population, but it is the only known comprehensive spiritual distress or suffering tool used by chaplains in collaboration with patients. A consideration could be whether a one question measure such as "Are you at peace?" (Steinhauser et al. 2006) yields the sense of spiritual suffering and coping desired by palliative care team members. There is no known validated decision-making scale utilized by palliative chaplains in the peerreviewed literature. There is, however, a growing call for chaplains to have a deepened and broader religious competency (Ragsdale 2018), especially when 
considering patient decision-making and the request for recommendations to palliative team members regarding religious and/or cultural language to use and not use.

Overall, this investigation yielded a good news/bad news narrative for palliative chaplains. The good news is that there was a robust valuing of the chaplaincy role for partnership in palliative care. This valuing of this role is evidenced by the valued investment of time, energy, and insight of the views and perceptions from busy and burdened clinicians to help improve palliative chaplain spiritual assessment progress notes. Their copious affirmation and generous investment in this process is a takeaway. While not having frequency numbers, it was also verbally acknowledged that palliative chaplain progress notes are read. The bad news, however, is that, "sometimes spiritual care has a reputation for not having a helpful note" and that what was being sought for by palliative partners in the note was often missing. Common sense informs that non-chaplain palliative team members will stop looking for treasure in a chaplain's spiritual assessment progress note if it is not there and/or easily found. Perhaps lending strength to the palliative care team model with the chaplain as a core member were the unsolicited comments offered about the chaplain having a "unique perspective" and generating "insights" that would not have arisen without the chaplaincy/patient conversation. Recognizing chaplains make a "deeper spiritual connection" (Lee et al. 2016), palliative chaplains need to continue to build competency toward constructing progress notes that transfer the outcomes of treasured patient/family relationships to information that has durable value for non-chaplain palliative team members.

\subsection{Limitations}

It is uncertain whether or to what extent the results are transferable beyond inpatient palliative care teams or the upper Midwest of the United States. Another clear limitation of this study is also that this convenience sample lacked gender, religious, as well as racial/ethnic diversity. A larger (geography, multisite) and more diverse purposive sample could lend more strength to the results. The samples of this research project were interprofessionals primarily based on inpatient palliative care teams, and this arguably influenced their contextualized reflections as compared to hospicebased practitioners or palliative providers from an outpatient context. As with any research project, this one also has undeniable bias. Selection bias is arguably present among those who voluntarily gave of their valuable time and insights to this process. It begs the question of whether the perceptions of those who were not there would have varied the results. Potentially also present was the response bias of social desirability due to Paul's role as chaplain on an inpatient palliative care team for 10 years. Paul had prior professional relationships with some of the participants within the various focus groups. 


\subsection{Implications}

With these contributions from non-chaplain palliative interprofessionals, there is a clear recommendation that chaplains continue to hone Domain 5 (religious, spiritual, existential) specialized information in a way that both quickly and thoroughly communicates how these data best inform palliative partners about decision-making and the suffering/coping experience of seriously ill patients and their loved ones.

An expansion of this project could also include the context of outpatient palliative care as well as with those non-chaplain staff members serving within the last chapter of palliative care, hospice. While this research did not intentionally differentiate pediatric palliative care responses within this study, another project could exclusively focus on those staff members. An inpatient nursing sample of focus group participants could be another critical source of information as nurses, traditionally, provide the highest volume of referrals (Galek et al. 2009) to chaplains. Last, to build on this research, focus groups of non-chaplain palliative care team members could gather to converse and seek feedback preferences for three or four different palliative chaplain spiritual assessment pre-formatted templates.

\section{Conclusion}

Bruce Rumbold, an Australian spiritual care specialist, offered, "Spiritual assessment tools should not be used without adequate exploration of the assumptions made. Assessment processes need to be adequately conceptualised and practically relevant" (Rumbold 2007, S60). This project began with the desire to address assumptions by exploring the perceptions of those who arguably most read palliative chaplain progress notes. With this information, palliative care chaplains can be more equipped to be evermore practically relevant to the shared work of enhancing quality of life and mitigating the suffering of those with serious illness. In the end, this work matters most when it makes an improved quality of life difference for all people with serious illness. When palliative care chaplains prioritize the stories of how existential, spiritual, and religious factors influence decision-making and suffering/coping, they not only help reduce that suffering; they uncover treasure that enriches the contribution of each person on the palliative care team.

Acknowledgments Research is ideally conducted among teams integrating their many contributions. Meriting the most gratitude are the research participants without whom this study would not have been possible. A word of thanks is also necessary to the advisory committee for the provision of their timely insight and sage counsel. A final expression of gratitude is extended to these guides and experts, Dick Krueger, PhD; Mary Anne Casey, PhD; Megan Winkler, APRN, PhD; Susan O’Conner-Von, RN-C, PhD; and Lex Tartaglia, DMin, BCC. The extension of their wisdom, scholarship, and willingness to share it with us made this work better. 
Funding Transforming Chaplaincy, funded by the Templeton Foundation, sponsored this project. Paul Galchutt was a Transforming Chaplaincy Research Fellow. Paul has also been a healthcare chaplain for 15 years, 10 of which were on an inpatient palliative care team at the University of Minnesota Medical Center. Paul's interest in palliative care spiritual assessment progress notes was spurred by the summons to develop one (Galchutt 2013, 2016). Judy Connolly was the comoderator and analysis partner for this research project. She has contributed to the development of interprofessional palliative care teams in conjunction with the Fairview Health Services Palliative Care Leadership Center established in 2003 by the Center to Advance Palliative Care. Judy and Paul have been healthcare chaplain colleagues for 12 years.

\section{References}

Association of Professional Chaplains. 2015. Standards of practice for professional chaplains. Retrieved June 18, 2018 from www.professionalchaplains.org/Files/professional_standards/ standards_of_practice/Standards_of_Practice_for_Professional_Chaplains_102215.pdf.

Balboni, T.A., M.E. Paulk, M.J. Balboni, A.C. Phelps, E.T. Loggers, A.A. Wright, et al. 2010. Provision of spiritual care to patients with advanced cancer: Associations with medical care and quality of life near death. Journal of Clinical Oncology 28 (3): 445.

Balboni, T., M. Balboni, M.E. Paulk, A. Phelps, A. Wright, J. Peteet, et al. 2011. Support of cancer patients' spiritual needs and associations with medical care costs at the end of life. Cancer 117 (23): 5383-5391.

Cassell, Eric J. 2004. The nature of suffering and the goals of medicine. 2nd ed. New York: Oxford University Press.

Choi, P.J., V. Chow, F.A. Curlin, and C.E. Cox. 2019. Intensive care clinicians' views on the role of chaplains. Journal of Health Care Chaplaincy 25 (3): 89-98.

Delgado-Guay, M.O., D. Hui, H.A. Parsons, K. Govan, M. De la Cruz, S. Thorney, and E. Bruera. 2011. Spirituality, religiosity, and spiritual pain in advanced cancer patients. Journal of Pain and Symptom Management 41 (6): 986-994.

Ernecoff, N.C., F.A. Curlin, P. Buddadhumaruk, and D.B. White. 2015. Health care professionals' responses to religious or spiritual statements by surrogate decision makers during goals-of-care discussions. JAMA Internal Medicine 175 (10): 1662-1669.

Ferrell, B.R., M.L. Twaddle, A. Melnick, and D.E. Meier. 2018. National consensus project clinical practice guidelines for quality palliative care guidelines. Journal of Palliative Medicine 21 (12): 1684-1689.

Fitchett, George. 2017. Next steps in spiritual assessment. [Power Point Slides]. Chicago.

Frank, Arthur W. 2010. Letting stories breathe: A socio-narratology. Chicago: University of Chicago Press.

Furtak, Rick A. 2005. Wisdom in love: Kierkegaard and the ancient quest for emotional integrity. Notre Dame: University of Notre Dame Press.

Galchutt, Paul. 2013. A palliative care specific spiritual assessment: How this story evolved. OMEGA-Journal of Death and Dying 67 (1-2): 79-85.

2016. Chaplaincy scope of practice note: The evolution of a specific palliative care spiritual assessment. PlainViews 13: 12.

Galek, K., L.C. Vanderwerker, K.J. Flannelly, G.F. Handzo, J. Kytle, A.M. Ross, and S.L. Fogg. 2009. Topography of referrals to chaplains in the metropolitan chaplaincy study. Journal of Pastoral Care and Counseling 63 (1-2): 1-13.

Krueger, Richard A., and Marie A. Casey. 2015. Focus groups: A practical guide for applied research. 5th ed. Thousand Oaks: Sage.

Lee, B.M., F.A. Curlin, and P.J. Choi. 2016. Documenting presence: A descriptive study of chaplain notes in the intensive care unit. Palliative \& Supportive Care 15 (2): 190-196. 
Monod, S.M., E. Rochat, C.J. Büla, G. Jobin, E. Martin, and B. Spencer. 2010. The spiritual distress assessment tool: An instrument to assess spiritual distress in hospitalised elderly persons. BMC Geriatrics 10 (1): 88.

Monod, S., E. Martin, B. Spencer, E. Rochat, and C. Büla. 2012. Validation of the spiritual distress assessment tool in older hospitalized patients. BMC Geriatrics 12 (1): 13.

National Consensus Project Clinical Practice Guidelines for Quality Palliative Care. 2013. Clinical practice guidelines for quality palliative care. 3rd ed. Retrieved June 18, 2018 from https:// www.nationalcoalitionhpc.org/ncp-guidelines-2013.

Pargament, Kenneth I. 2001. The psychology of religion and coping: Theory, research, practice. New York: Guilford Press.

Puchalski, C., B. Ferrell, R. Virani, S. Otis-Green, P. Baird, J. Bull, et al. 2009. Improving the quality of spiritual care as a dimension of palliative care: The report of the Consensus Conference. Journal of Palliative Medicine 12 (10): 885-904.

Ragsdale, J.R. 2018. Transforming chaplaincy requires transforming clinical pastoral education. Journal of Pastoral Care \& Counseling 72 (1): 58-62.

Rumbold, B.D. 2007. A review of spiritual assessment in health care practice. Medical Journal of Australia 186: S60-S62.

Steinhauser, K.E., C.I. Voils, E.C. Clipp, H.B. Bosworth, N.A. Christakis, and J.A. Tulsky. 2006. "Are you at peace?": One item to probe spiritual concerns at the end of life. Archives of Internal Medicine 166 (1): 101-105.

Tartaglia, A., D. Dodd-McCue, T. Ford, C. Demm, and A. Hassell. 2016. Chaplain documentation and the electronic medical record: A survey of ACPE residency programs. Journal of Health Care Chaplaincy 22 (2): 41-53.

Wirpsa, J.M., E.R. Johnson, J. Bieler, L. Boyken, K. Pugliese, E. Rosencrans, and P. Murphy. 2019. Interprofessional models for shared decision making: The role of the health care chaplain. Journal of Health Care Chaplaincy 25 (1): 20-44.

Open Access This chapter is licensed under the terms of the Creative Commons Attribution 4.0 International License (http://creativecommons.org/licenses/by/4.0/), which permits use, sharing, adaptation, distribution and reproduction in any medium or format, as long as you give appropriate credit to the original author(s) and the source, provide a link to the Creative Commons license and indicate if changes were made.

The images or other third party material in this chapter are included in the chapter's Creative Commons license, unless indicated otherwise in a credit line to the material. If material is not included in the chapter's Creative Commons license and your intended use is not permitted by statutory regulation or exceeds the permitted use, you will need to obtain permission directly from the copyright holder.

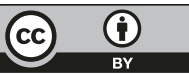

